\title{
The effects of Temporary Portocaval shunt during live donor liver transplantation on the hemodynamic and laboratory parameters of the anhepatic and reperfusion phases.
}

N. Hussain1, H. Soliman2, H. Saied1, K. Yassen1, 1 Anesthesia department, 2 Surgery department National Liver Institute - Menofia University, Egypt.

\section{Background and Aim of Study}

Temporary Portocaval shunt (TPCS) is a surgical procedure to help reduce gut congestion in post dissection phase of LDLT. Aim: Is to evaluate the effects of TPCS on systemic hemodynamic and laboratory parameters during the anhepatic and reperfusion phases

\section{Materials and Methods}

Randomized control study, ethical comity approval, consent applied, registered (PACT201712002857722). 64 LDLT, (4 excluded extended portal vein thrombosis), TPCS gp $(n=30)$, Control C gp $(n=30)$. Post induction, Trans esophageal Doppler(TED) probe at mid esophagus were applied.

Hemodynamics,TED parameters(cardiac output $\mathrm{CO} \mathrm{l} / \mathrm{min}$, systemic vascular resistance SVR dyns/s/cm-5 $\backslash \mathrm{min}$ ), arterial blood gases $(\mathrm{pH}$, bicarbonate $\mathrm{HCO} 3$ $\mathrm{mmol} / \mathrm{l})$, serum lactate $(\mathrm{mg} / \mathrm{dl})$, dose of inotropic drugs were reported at: post induction (T0), end anhepatic phase (T1) and 5 min post reperfusion(T2).

Postoperative ICU stay and complications were reported.

\section{Discussion}

More total Norepinephren support were required early in the anhepatic phase and throughout the procedure guided by TED to support mean BP and SVR in C gp vs,TPCS gp. Significantly less epinephrine boluses during (T2) were required in TPCS gp vs., $\mathrm{C}$ gp also, less blood products were indicated in TPCS gp. Although longer warm ischemia time(WIT) in TPCS gp vs. C gp postoperative liver enzymes were higher in C gp.

\section{Conclusion}

TPCS helps reducing acidosis and improving hemodynamic stability during the anhepatic phase of LDLT and immediately after reperfusion with less need for vasopressor support.

\begin{tabular}{|l|l|l|l|l|l|} 
& AGE / y & MELD & $\begin{array}{l}\text { W IT } \\
\text { /min }\end{array}$ & $\begin{array}{l}\text { ICU Stay } \\
\text { /d }\end{array}$ & $\begin{array}{l}\text { Lactate/ } \\
\mathrm{mg} / \mathrm{dl}\end{array}$ \\
\hline C gp & 46.3 & 15.4 & 40 & 10.4 & 63.4 \\
\hline $\begin{array}{l}\text { TPCS } \\
\text { gp }\end{array}$ & 46.8 & 16.4 & 50 & 8.8 & 29.8 \\
\hline
\end{tabular}

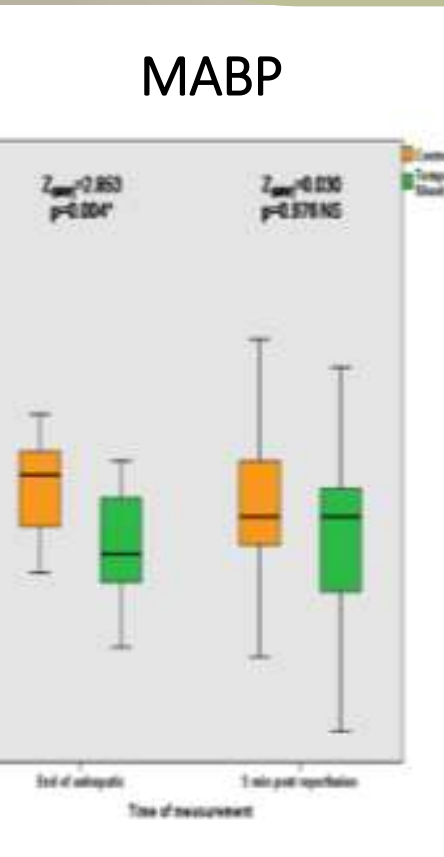

Epinephrine

sti"

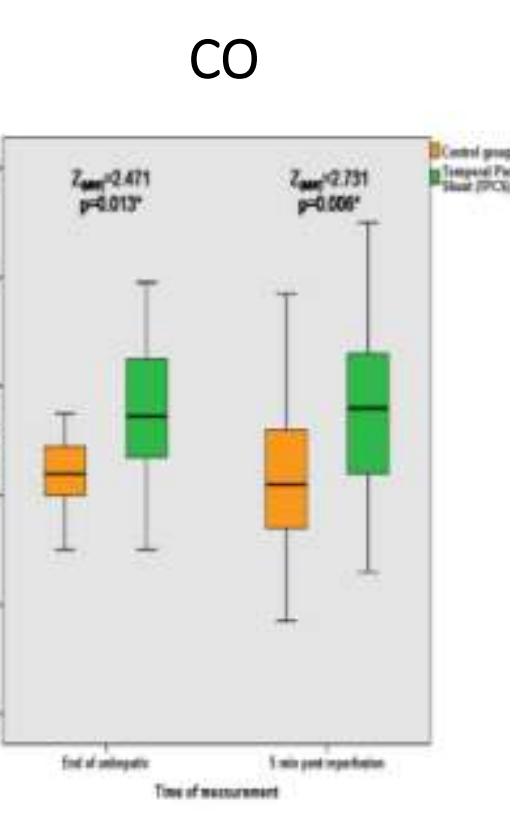

Norepinephren

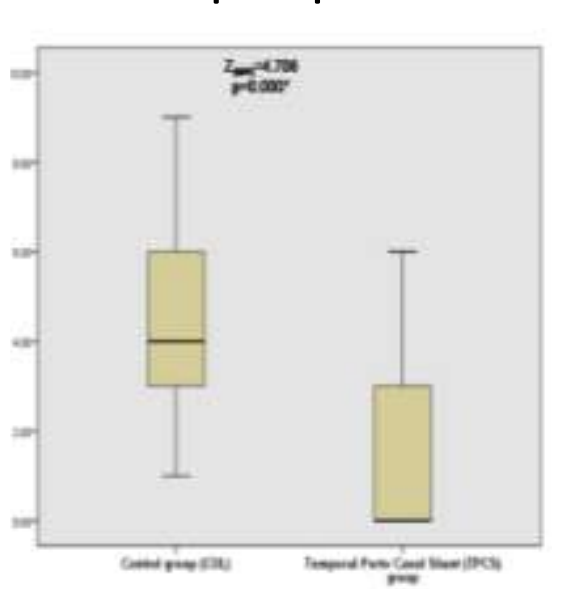

SVR

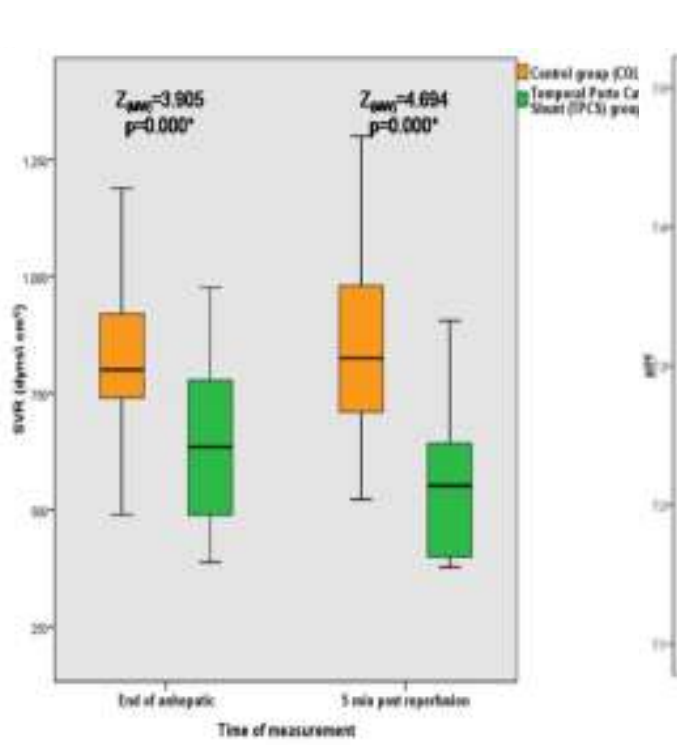

CRYO ppt unit sait:
$\mathrm{pH}$

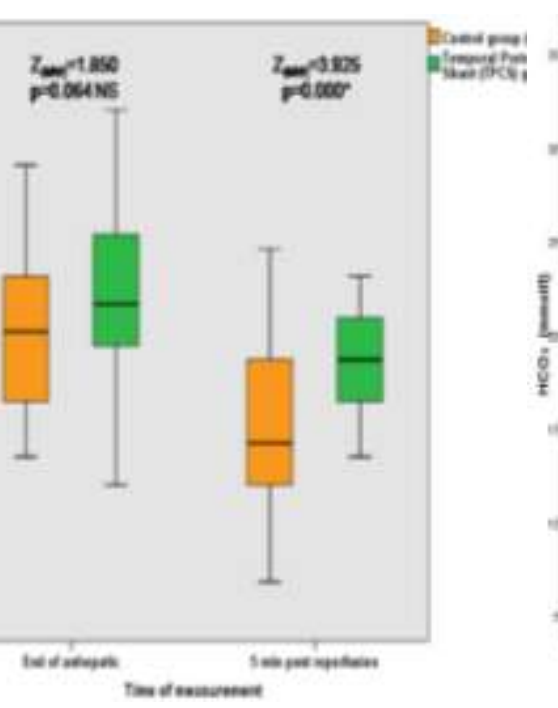

PRBC unit

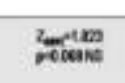



ALT
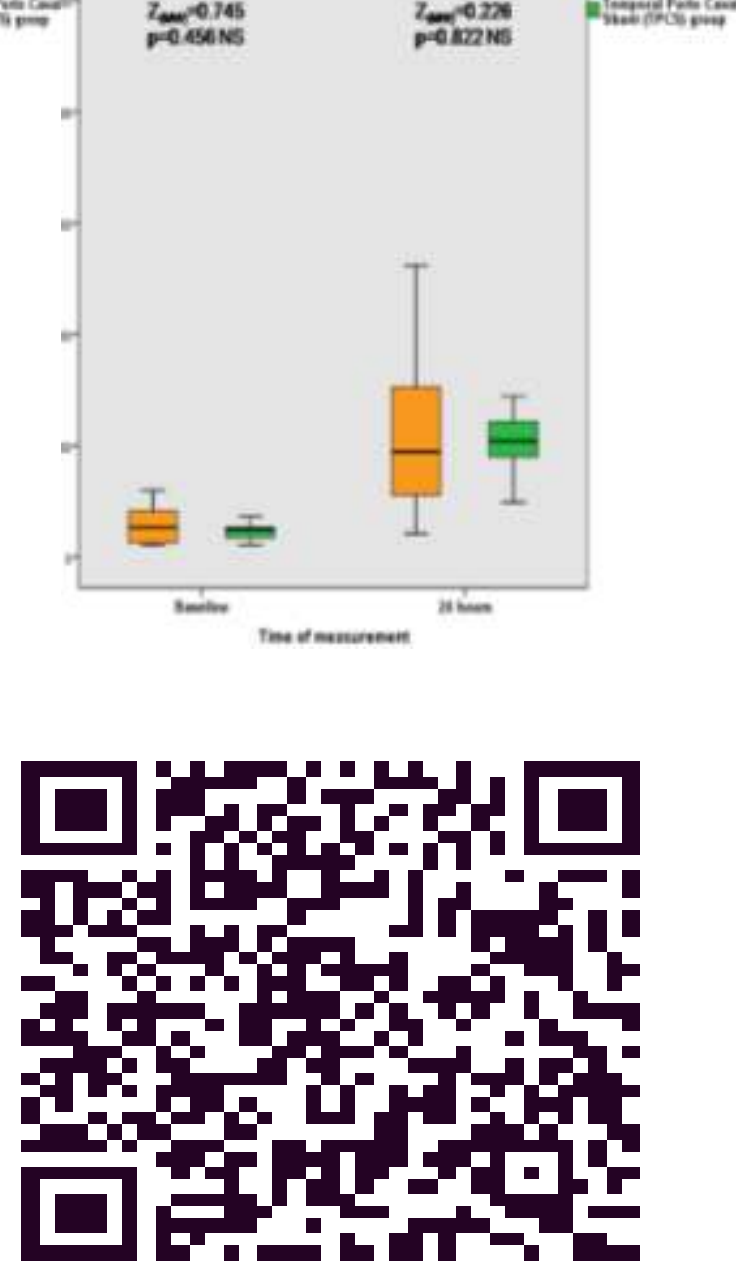